\title{
Durable partial reinforcement effect and social dominance in two inbred mouse strains*
}

\author{
C. T. LEE†, PAUL T.P. WONG $\dagger \dagger$, and JAWSY CHEN \\ University of Texas, Austin, Texas 78712
}

\begin{abstract}
The partial reinforcement effect (PRE) was investigated in C57BL/10J (C57) and DBA/2J (DBA) inbred mice in a straight runway. The PRE was obtained in both strains and was sustained through extended extinction and continuously reinforced (CRF) reacquisition. Two weeks after the completion of the second runway extinction test, PRF and CRF Ss of each strain were pitched against each other in a tube dominance test. PRF Ss won a significantly greater number of the contests.
\end{abstract}

The employment of genetically defined groups of animals, such as inbred strains of mice, as Ss in investigating learning phenotypes not only allows the investigator to estimate the relative contribution by the genetic factor but also permits opportunities to test the generality of laws of learning. A previous investigation (Wong, Lee, \& Novier, 1971) demonstrated (a) the partial reinforcement effect (PRE) in two inbred strains of mice, C57BL/10J (C57) and DBA/2J (DBA), and (b) the durable PRE in that this effect can be sustained through blocks of extinction trials and CRF reacquisition training in both strains. The durable PRE has also been reported in rats by Traupmann, Wong, and Amsel (1971), Amsel, Wong, and Traupmann (1971), and Wong, Traupmann, and Brake (1974).

The purpose of the present experiment was threefold. The first aim was to insure that the durable PRE described by Wong et al (1971) was not due to the artifact of an initial short extinction period. Thus, in the present experiment, the first extinction training was extended into 48 nonrewarded trials. The second purpose was to determine if the strain difference reported by Wong et al (1971) could be obtained when the degree of food deprivation between the two strains was equated. The final aim was to ascertain if the PRE could survive the second extinction training and affect the outcome of a tube dominance test as described by Lindzey, Winston, and Manosevitz (1961).

\section{METHOD}

\section{Subjects}

The Ss were 10 male mice from each of the DBA and C57 strains purchased from the Jackson Laboratory. Upon arrival, they were individually housed in polypropylene cages and

*The research was supported by NSF University Science Development Program Grant GU-1598 and NSF Grant GB-14990X to A. Amsel. The publication of this paper was supported by Grant $1027 \mathrm{E}$ to $\mathrm{C}$. T. Lee and Trent University President's NRC Grant to P.T.P. Wong. Reprint requests should be sent to $C$. T. Lee.

tNow at the Department of Psychology, Brooklyn College of the City University of New York, Brooklyn, New York 11210. + Now at the Department of Psychology, Trent University, Peterborough, Ontario, Canada. K9J 7 B8. maintained ad lib on Purina Chow and water. The experimental training commenced when the Ss were approximately 50 weeks of age. Ss of each strain were evenly and randomly divided into two groups: CRF and PRF.

\section{Apparatus}

The runway was constructed of plywood, painted gray and covered with clear Plexiglas lids. It was $45 \times 3 \times 3$ in. Two guillotine doors formed a 6 -in.-long startbox and a 1 -ft-long goal compartment. On the end wall, 1 in. above the runway floor, was a metal foodcup $1 / 2$-in. deep and extending the width of the runway. Three $1-\mathrm{ft}$-runway time measures were obtained by means of photoelectric circuitry. The dominance test apparatus consisted of a Plexiglas tube, 1 in. inside diam and $17 \mathrm{in.}$ long, with a partition door in the center. The tube was connected at each end to a goalbox that was $4 \times 4 \times 2$ in. and covered by a clear Plexiglas lid.

\section{Procedure}

Deprivation and Handling. Each $\mathrm{S}$ was given $0.5 \mathrm{~g}$ of lab chow in the first 2 days of food deprivation. Thereafter, food ration for each $\mathrm{S}$ was adjusted according to the difference between $80 \%$ of ad lib body weight (X) and the daily body weight (Y). The amount of food given was $(Y-X) \pm 0.5,1,2$, or $3 \mathrm{~g}$ depending on the value of $(\mathrm{Y}-\mathrm{X})$. If $(\mathrm{Y}-\mathrm{X})$ was equal to or less than $0,3 \mathrm{~g}$ of food were given. However, if $(\mathrm{Y}-\mathrm{X})$ was greater than $4,3,2$, or $1 \mathrm{~g}, .5, .5,1$, or $2 \mathrm{~g}$ of food were given, respectively. Three weeks later, when their body weights stabilized at approximately $80 \%$ of their predeprivation ad lib body weights, experimental training began. Thereafter, the Ss were given approximately $3 \mathrm{~g}$ of food per day, including the food reinforcement received in the runway; their body weights were monitored from time to time to insure that they were maintained at the $80 \%$ weight level.

During the first 3 weeks of food deprivation, each $\mathrm{S}$ was handled a few minutes each day. Handling consisted of placing the $S$ in the palm and gently stroking the back of the $S$.

Runway Training. The Ss were given one 5-min pretraining trial, during which each $S$ was placed in the center of the goalbox, facing the foodcup, and allowed to eat a 45-mg Noyes pellet. During the experimental training, each $\mathrm{S}$ was given one trial per day for 4 days and four trials per day during the remaining days. On each trial, the start door was raised only when $\mathrm{S}$ was oriented toward it. The retrace door was lowered when the last photobeam was interrupted. A maximum of $3 \mathrm{~min}$ was allowed to traverse the 3 -ft alley. If the $\mathrm{S}$ failed to enter the goalbox within the alloted time, it was gently guided into it. On nonreward (N) trials, goal confinement was $30 \mathrm{sec}$, during which the foodcup was present but no food was available. On rewarded (R) trials, $\mathrm{S}$ was removed from the goalbox as soon as it finished consuming a $45-\mathrm{mg}$ food pellet. If it failed to consume the pellet 
in $3 \mathrm{~min}$, it was removed from the goalbox. For the PRF group, $\mathrm{N}$ trials occurred $50 \%$ of the time, as determined by a quasirandom sequence such that over eight blocks of four trials, $\mathrm{R}-\mathrm{R}, \mathrm{R}-\mathrm{N}, \mathrm{N}-\mathrm{N}$, and N-R, transitions were equiprobable.

During acquisition training, the Ss were run 6 days a week; however, they were run 7 days a week during extinction to minimize spontaneous recovery. On each training day, the running sequence for all Ss was randomized.

Tube Dominance Test. Two weeks after the completion of the second extinction test, each $\mathrm{S}$ was given one reinforced trial per day for 4 successive days in the tube. The procedure consisted of placing the $\mathrm{S}$ in one of the two identical endboxes, and allowing it to traverse the tube and enter the other endbox for a $45-\mathrm{mg}$ pellet. All Ss had two reinforced trials starting from one endbox, and two reinforced trials, starting from the other endbox.

During the dominance test, all PRF Ss had equal chance to compete with all CRF Ss of the same strain. Thus, each $S$ entered five contests, involving five different opponents. In each contest, one PRF $S$ and one CRF $S$ were placed in the two endboxes. The end doors were opened simultaneously only when both Ss were oriented toward the door. As soon as both Ss reached the middle section of the tube, the middle partition was opened. If the Ss squeezed by each other, they were placed back in their respective endboxes for another trial. The $S$ who was pushed back to its starting box was counted as the loser in that contest. A S was classified as dominant if he won at least three out of the five contests.

\section{RESULTS AND DISCUSSION}

\section{Runway Data}

Since analyses of variance on individual measures showed similar results, only total runway speeds (3.0/total time) are presented in Fig. 1 .

Acquisition. The DBAs ran significantly faster as supported by a main effect of strain $[F(1,16)=15.59$, $\mathrm{p}<.01]$ and a Strain by Trial Blocks interaction $[F(19,816)=7.43, p<.01]$. This finding is consistent with that reported by Wong et al (1971). However, in the present study, the superiority of DBAs cannot be attributed to differences in deprivation level, since both strains were equated in body weight loss. Thompson (1953) reported that DBAs were more emotional than $\mathrm{C} 57 \mathrm{~s}$ in an open-field situation. The superior performance of DBAs could be due to a higher level of excitability or arousal. Another possible explanation is that $\mathrm{C} 57 \mathrm{~s}$ are slow learners in the appetitively motivated learning situation. Both Sprott (1972) and Bovet, Bovet-Nitti, and Oliverio (1969) have observed that C57BL/6J mice, which are genetically very closely related to our $\mathrm{C} 57 \mathrm{BL} / 10 \mathrm{~J}$, are poorer learners than $\mathrm{DBA} / 2 \mathrm{~J}$ mice in certain learning situations.

During acquisition, the mean number of retraces for C57s and DBAs was 1.6 and .3 , respectively $(t=6.23$, $\mathrm{p}<.01)$. This finding again confirmed the previous result obtained by Wong et al (1971). These retrace data indicate that the $\mathrm{C} 57 \mathrm{~s}$ were slower in dropping competing responses, thus lending some support to the slow-learner interpretation. If this interpretation is indeed correct, one would predict that, with extended acquisition training, the $\mathrm{C} 57 \mathrm{~s}$ should reach the same asymptote as the DBAs.

Extinction I. The PRE was apparent in both strains, and was confirmed by a main effect of reinforcement $[F(1,16)=13.40, p<.01]$. The main effect of strain was not significant.

CRF Reacquisition. All groups reacquired the running response $(F(3,240)=67.67, p<.01]$. The main effect of strain was not significant. The graph clearly showed that both DBAs and C57s reached approximately the same asymptotic level. This finding lends further support to the notion that the inferior performance of C57s during the initial acquisition was not due to a lower drive level but a slower rate of learning.

Extinction II. The PRE was again apparent and was confirmed by a significant reinforcement main effect $[F(1,16)=10.77, p<.01]$. The present finding of a durable PRE cannot be attributed to an inadequate length of initial extinction training, since at the end of Extinction I, there was no significant difference in the four groups.

\section{Tube Dominance Tests}

Nine out of 10 PRF Ss were dominant. The probability of this occurring is less than .05 . Out of a

Fig. 1.

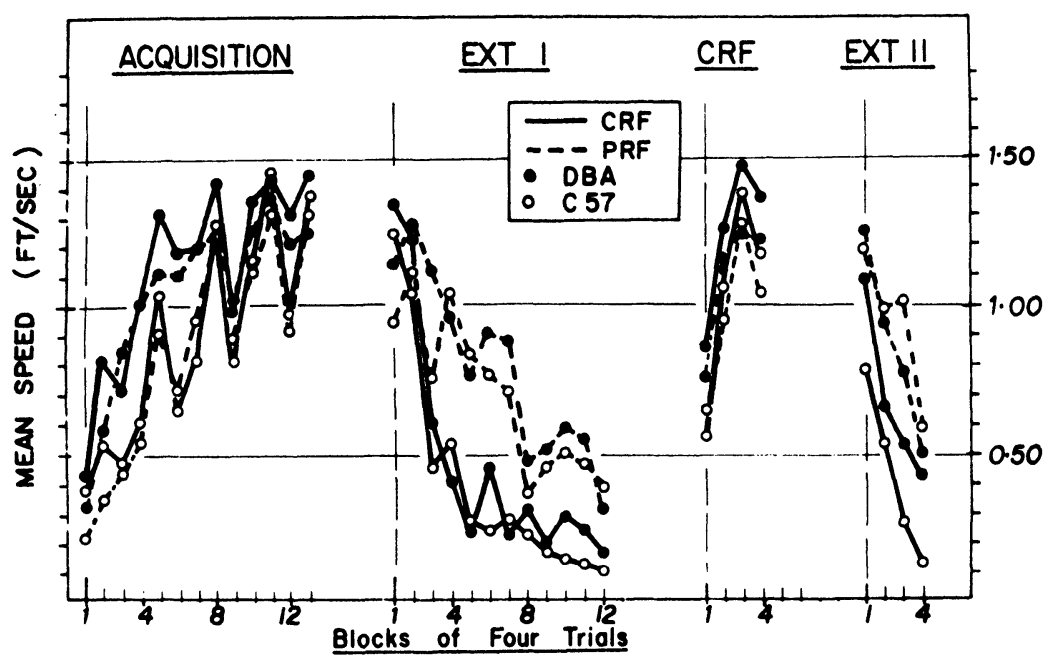


total of 50 contests, the PRF Ss won $38\left(\chi^{2}=13.52\right.$, $\mathrm{p}<.01)$. Thus, prior PRF training in a runway situation tends to produce winners in the tube dominance test.

The transfer of persistence from a nonsocial runway situation to a completely different tube-competition situation is of great theoretical interest. The tube dominance test is essentially an extinction test, because food reward is withheld during the test and the passage is blocked by another animal. The fact that more PRF Ss persisted in approaching the empty endbox can be considered as a manifestation of the PRE. This transfer of the PRE across drastically different situations, and after two sessions of extinction and two sessions of CRF training, further attests to the remarkable durability of the PRE in both strains of mice. This transfer of long-term persistence effects supports Amsel's frustration theory (Amsel, 1967), which attributes the transfer to conditioned anticipatory frustration $\left(\mathrm{r}_{\mathrm{F}}-\mathrm{S}_{\mathrm{F}}\right)$. According to this theory, once an approach response becomes conditioned to $r_{F}-s_{F}$ (i.e., $s_{F} \rightarrow$ approach), whenever $r_{F}-S_{F}$ is conditioned to a subsequent situation, it will mediate the approach response. The present finding also supports the contention that $s_{F} \rightarrow$ approach mechanism does not become dissociated during extinction (e.g., Traupmann et al, 1971).

Viewed from a different angle, it seems that prior PRF training has some effects on aggressive behavior. When the two contestants meet in the center of the tube, they tend to push and sometimes attack each other. It is possible that the PRF Ss are more persistent in "fighting," consequently they win out. If prior PRF training in the runway indeed produces more tenacious "fighters" and more dominant animals, it will provide evidence that effects of PRF training can transfer across different response systems. It will also follow that different histories of reinforcement in a nonsocial learning situation may change the social hierarchy of animals. However, in the present tube test, the effect of prior PRF training on aggressive behavior and social hierarchy cannot be assessed independently of its effects on resistance to extinction.

\section{REFERENCES}

Amsel, A. Partial reinforcement effects on vigor and persistence: Advance in frustration theory derived from a variety of within-subjects experiments. In K. W. Spence and J. T. Spence (Eds.), The psychology of learning and motivation. Vol. 1. New York: Academic Press, 1967, Pp. 1-65.

Amsel, A., Wong, P. T. P., \& Traupmann, K. L. Short-term and long-term factors in extinction and durable persistence. Journal of Experimental Psychology, 1971, 90, 90-95.

Bovet, D., Bovet-Nitti, F., \& Oliverio, A. Genetic aspect of learning and memory in mice. Science, $1969,163,139-149$.

Lindzey, G., Winston, H., \& Manosevitz, M. Social dominance in inbred mouse strains. Nature (London), 1961, 191, 474-476.

Sprott, R. L. Passive-avoidance conditioning in inbred mice: Effects of shock intensity, age and genotype. Journal of Comparative \& Physiological Psychology, 1972, 80, 327-334.

Thompson, W. $R$. The inheritance of behavior: Behavioral differences in fifteen mouse strains. Canadian Journal of Psychology, 1953, 7, 145-155.

Traupmann, K. L., Wong, P. T. P., \& Amsel, A. Durability of persistence as a function of number of partially reinforced trials. Journal of Experimental Psychology, 1971, 88, 372-375.

Wong, P. T. P., Lee, C. T., \& Novier, F. H. The partial reinforcement effect (PRE) sustained through extinction and continuous reinforcement in two strains of inbred mice. Psychonomic Science, 1971, 22, 141-143.

Wong, P. T. P. Traupmann, K. L., \& Brake, S. Does delay of reinforcement produce durable persistence? Quarterly Journal of Experimental Psychology, 1974, 26, 1-11.

\title{
Vowels and consonants as targets in the search of single words*
}

\author{
CARLTON T. JAMES $\dagger$ \\ Rutgers University, New Brunswick, New Jersey 08903
}

\begin{abstract}
Ss searched four- and six-letter words typed in uppercase for predesignated target letters, Reaction times to vowel targets were faster than to consonant targets for both stimulus lengths; this was true whether or not the target was contained in the stimulus word. The results are interpreted to indicate that an early stage in word perception is the location of vowels, as proposed by Hansen and Rogers, 1968.
\end{abstract}

In a study of visual search of lowercase words, James

\footnotetext{
*This research was supported by NSF University Science Development Program, Grant GU 1598, to the University of Texas at A ustin. Preparation of the manuscript was facilitated by support from the Rutgers University Research Council. The author wishes to express his appreciation to David Smith for his assistance and to Kathryn T.Spoehr for her comments.

tRequests for reprints should be sent to Carlton $T$. James, Psychology Department, Rutgers College, New Brunswick, New Jersey 08903.
}

and Smith (1970) found that predesignated vowel targets were found faster than consonant targets. Since the difference disappeared with nonword stimuli, James and Smith concluded that the vowel advantage was somehow connected with the structure of words. They suggested that vowels occur in more predictable orthographic contexts than consonants, and a 